\title{
A comparison of 12-gene colon cancer assay gene expression in African American and Caucasian patients with stage II colon cancer
}

Rangaswamy Govindarajan ${ }^{1 * \dagger}$, James Posey ${ }^{2 \dagger}$, Calvin Y. Chao ${ }^{3}$, Ruixiao Lu ${ }^{3}$, Trafina Jadhav ${ }^{2}$, Ahmed Y. Javed ${ }^{4}$, Awais Javed ${ }^{4}$, Fade A. Mahmoud ${ }^{1}$, Raymond U. Osarogiagbon ${ }^{4}$ and Upender Manne ${ }^{2^{*}}$

\begin{abstract}
Background: African American (AA) colon cancer patients have a worse prognosis than Caucasian (CA) colon cancer patients, however, reasons for this disparity are not well understood. To determine if tumor biology might contribute to differential prognosis, we measured recurrence risk and gene expression using the Oncotype DX ${ }^{\circledR}$ Colon Cancer Assay (12-gene assay) and compared the Recurrence Score results and gene expression profiles between AA patients and CA patients with stage II colon cancer.
\end{abstract}

Methods: We retrieved demographic, clinical, and archived tumor tissues from stage II colon cancer patients at four institutions. The 12-gene assay and mismatch repair (MMR) status were performed by Genomic Health (Redwood City, California). Student's t-test and the Wilcoxon rank sum test were used to compare Recurrence Score data and gene expression data from AA and CA patients (SAS Enterprise Guide 5.1).

Results: Samples from $122 \mathrm{AA}$ and 122 CA patients were analyzed. There were 118 women (63 AA, 55 CA) and 126 men (59 AA, 67 CA). Median age was 66 years for AA patients and 68 for CA patients. Age, gender, year of surgery, pathologic T-stage, tumor location, the number of lymph nodes examined, lymphovascular invasion, and MMR status were not significantly different between groups $(p=0.93)$. The mean Recurrence Score result for AA patients $(27.9 \pm 12.8)$ and CA patients $(28.1 \pm 11.8)$ was not significantly different and the proportions of patients with high Recurrence Score values ( $\geq 41)$ were similar between the groups (17/122 AA; 15/122 CA). None of the gene expression variables, either single genes or gene groups (cell cycle group, stromal group, BGN1, FAP, INHBA1, Ki67, MYBL2, CMYC and GADD45B), was significantly different between the racial groups. After controlling for clinical and pathologic covariates, the means and distributions of Recurrence Score results and gene expression profiles showed no statistically significant difference between patient groups.

Conclusion: The distribution of Recurrence Score results and gene expression data was similar in a cohort of AA and CA patients with stage II colon cancer and similar clinical characteristics, suggesting that tumor biology, as represented by the 12-gene assay, did not differ between patient groups.

Keywords: Colon cancer, 12-gene assay, Gene expression, Stage II, African-American, Caucasian

\footnotetext{
* Correspondence: govindarajanrang@uams.edu; upendermanne@uabmc.edu

${ }^{\dagger}$ Equal contributors

'University of Arkansas for Medical Sciences, 4301 W Markham, Slot 508,

Little Rock, AR 72205, USA

${ }^{2}$ University of Alabama at Birmingham Comprehensive Cancer Center,

Birmingham, AL, USA

Full list of author information is available at the end of the article
} 


\section{At a glance}

- Tumor biology as reflected in differential gene expression may contribute to differential outcomes for African-American patients as compared to Caucasian colon cancer patients.

- A cohort of patients well balanced for clinical and demographic factors was selected for gene expression testing using the Oncotype DX colon cancer assay as a measure of tumor biology.

- The distribution of Recurrence Score results for African-American patients $(n=122)$ was not significantly different than that of Caucasian patients $(n=122)$.

- Expression of single genes or gene groups (cell cycle group, stromal group, BGN1, FAP, INHBA1, Ki67, MYBL2, cMYC and GADD45B) also did not differ significantly between ethnic groups.

- Although differences in outcomes have been observed between AA and CA patients, this study found no difference in tumor biology as represented by the 12-gene assay when no differences in demographic or clinical factors were present.

\section{Background}

Racial disparities in the outcomes of many cancers are a well-recognized phenomenon. Although the survival of patients with colorectal cancer has improved in recent years, disparity in outcomes between African American (AA) and Caucasian (CA) patients persists [1]. This may be due to a variety of factors, such as socioeconomic factors influencing access to good quality care, differences in screening participation, or tumor biology [2-5].

The Oncotype $\mathrm{DX}^{\odot}$ Colon Cancer Assay (12-gene assay, Genomic Health, Inc., Redwood City, California) is a 12-gene RT-PCR based test that yields a Recurrence Score ${ }^{\circ}$ result that has been clinically validated to predict the probability of recurrence following resection of stage II and stage III colon cancer [6-8]. The 12 genes measured consist of 7 cancer-related genes, which include 3 cell cycle genes (MK167, MYBL2, and MYC), 3 stromal genes (BGN, INHBA and FAP), and an early response gene (GADD45B), and 5 reference normalization genes. The Recurrence Score result (ranging from 0 to 100 with lower values representing lower risk of recurrence) is derived from RNA expression levels of these genes as determined by RT-PCR in formalin-fixed paraffin-embedded (FFPE) tumor tissue using a quantitative algorithm. The assay has been shown to add significant information beyond conventional clinical and pathologic factors regarding the risk of recurrence and has been shown to be clinically valid in multiple studies [6-8].

The distribution of Recurrence Score ${ }^{\circ}$ results and associated gene expression profiles based on race/ethnicity have not been previously assessed. We used the 12-gene assay as a measure of gene expression activity to evaluate possible biological differences between AA and CA patients with resected stage II colon cancer.

\section{Methods}

Patients with resected stage II colon cancer and with archived tumor tissue were identified from tumor registries at four institutions (University of Arkansas for Medical Sciences, Little Rock, AR; Central Arkansas Veterans Healthcare System, Little Rock, AR; University of Tennessee Cancer Institute, Memphis, TN; and the University of Alabama at Birmingham, Birmingham, AL). Institutional Review Board approval was obtained from the respective institutions. Demographic and clinical data, including pathologic stage, was obtained by manual chart review. Two hundred ninety three stage II colon cancer patients, matched for the year of diagnosis, age, and sex, were selected for the study. Race/ethnicity was selfreported. Patients with rectal cancer and those with synchronous tumors were excluded from the study. Paraffin blocks or unstained sections on slides were obtained for the selected patients. After verification of the diagnosis and stage by an independent pathologist, the 12-gene assay and mismatch repair status (MMR) by immunohistochemistry for MLH1 and MSH2 were performed on these samples at the Genomic Health laboratory.

\section{Statistical methods}

\section{Primary analysis}

To address the primary objective of the study, the distributions of the Recurrence Score results for AA and CA patients were compared. Specifically, t-tests for two independent samples were used to determine if there were significant differences between the Recurrence Score results and the expression of individual genes in the two patient groups. If the normality assumption of the distributions of the Recurrence Score results was found to be invalid, a nonparametric Wilcoxon rank-sum test was used. In addition, the Recurrence Score distributions by race were summarized using histograms and descriptive statistics, such as means, medians, standard deviations, and ranges. Similar analyses were carried out to compare the expression levels of gene groups and individual genes within the 12-gene assay between the two patient groups.

\section{Secondary analyses}

We compared the distribution of demographic and pathology variables between AA and CA patients using Chi-square tests for categorical variables and two-sided t-tests for continuous variables. We also compared the distributions of the Recurrence Score results, gene groups and individual genes between the two patient groups, 
controlling for demographic and pathologic characteristics. We used multiple linear regression models to evaluate the relationships of the continuous Recurrence Score value, gene groups, and individual genes to relevant demographic and pathologic covariates, including race, gender, age at surgery, number of nodes examined, pathologic $\mathrm{T}$ stage, MMR status, and lymphatic vascular invasion (LVI).

All tests of hypotheses were conducted at a two-sided alpha level of 0.05 unless otherwise noted. In this exploratory study, we have made no adjustments for multiple comparisons. All analyses were conducted with SAS 9.3 (SAS Institute, Cary, NC).

\section{Results}

Stage II colon cancer patients $(n=293)$ were selected from tumor registries of four institutions (Fig. 1). Forty patients were excluded from analysis at pathology review (24 with insufficient or no invasive cancer, 5 with rectal cancer, 4 with no lymph node data, 2 with appendicular cancers and 5 for other reasons). Six patients were excluded due to laboratory failures (4 for insufficient RNA and 2 for poor quantitative PCR quality), and 3 patients were excluded due to missing MMR testing results. The remaining 244 samples (from $122 \mathrm{AA}$ and $122 \mathrm{CA}$ patients) were used in the analysis. The racial distribution of patients from each institution is listed in Fig. 1.

In the cohort of 244 patients, there were 118 women (63 AA, 55 CA) and 126 men (59 AA, 67 CA) (Table 1).
The median age at surgery was 66 years (range 35-88 years) for AA patients, and 68 years (range 40-97 years) for CA patients. Surgery was performed before the year 2000 in $31 \%$ of AA and CA patients, from 2000 to 2009 in $40 \%$ of AA and $49 \%$ of CA patients, and from 2010 onwards in $29 \%$ of AA and $20 \%$ of CA patients. Table 1 shows the distribution of the demographic, clinical, and pathological characteristics of the patients eligible for analysis. Age, gender, year of surgery, pathologic stage, tumor location, number of nodes examined, LVI, and MMR status were not significantly different between the two racial groups as determined by Chi-square tests.

The mean Recurrence Score result was $27.9 \pm 12.8$ for the AA group and $28.0 \pm 11.8$ for the CA group and was not significantly different between groups $(p=0.93)$ (Fig. 2). The proportion of patients with a high Recurrence Score result $(\geq 41)$ was similar between the groups: 17/122 (14 \%) for AA patients and 15/122 (12 \%) for CA patients (Fig. 3). None of the gene expression variables, either single genes or gene groups (Cell Cycle group, Stromal group, BGN, FAP, INHBA, Ki67, MYBL2, C-MYC, and GADD45B) was significantly different between the racial groups $(p>0.05$ for all individual genes and gene groups) (Fig. 4).

Linear regression modeling of Recurrence Score result, gene groups, and individual genes with the explanatory variables including race, clinical covariates, and pathological covariates (including number of nodes examined,

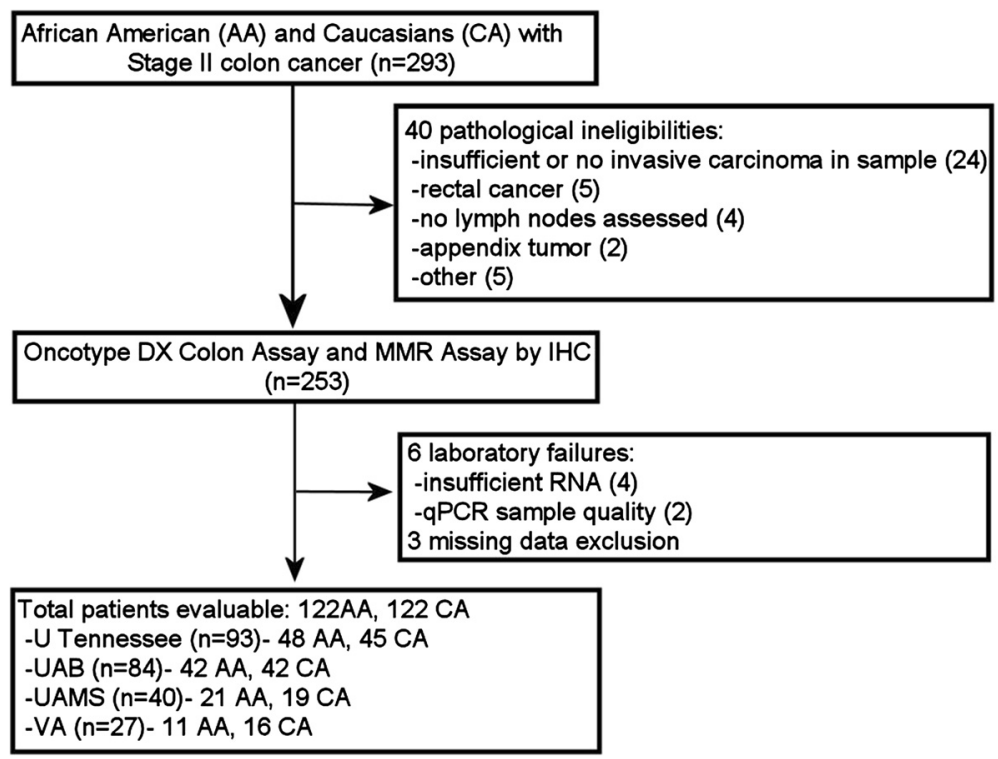

Fig. 1 CONSORT diagram for the study. Study cohort of subjects selected for the study after exclusion of those who did not meet the selection criteria. The analysis was based on 244 samples (122 Caucasian patients and 122 African-American patients). IHC: immunohistochemistry; U Tennessee: University of Tennessee; UAB: University of Alabama Birmingham; UAMS: University of Arkansas for Medical Sciences; VA: Central Arkansas Veterans Healthcare System 
Table 1 Demographic and clinical characteristics

\begin{tabular}{|c|c|c|}
\hline Characteristics & African American (AA) & Caucasian (CA) \\
\hline \multicolumn{3}{|l|}{ Age at Surgery (Yrs.) } \\
\hline Median (Range) & $66(35,88)$ & $68(40,97)$ \\
\hline IQR (1 $1^{\text {st }}$ quartile, $3^{\text {rd }}$ quartile) & $21(55-76)$ & $20(57-77)$ \\
\hline \multicolumn{3}{|l|}{ Gender } \\
\hline Female $(n=118)$ & $63(51.6 \%)$ & 55 (45.1\%) \\
\hline Male $(n=126)$ & $59(48.4 \%)$ & 67 (54.9\%) \\
\hline \multicolumn{3}{|l|}{ Surgery Year } \\
\hline$<2000$ & $38(31.2 \%)$ & $38(31.2 \%)$ \\
\hline$\geq 2000$ and $<2010$ & $49(40.2 \%)$ & $60(49.2 \%)$ \\
\hline$\geq 2010$ & $35(28.7 \%)$ & $24(19.7 \%)$ \\
\hline \multicolumn{3}{|l|}{ Number of Nodes Examined } \\
\hline Median (Range) & $15(1,52)$ & $17(1,50)$ \\
\hline IQR (1 $1^{\text {st }}$ quartile, $3^{\text {rd }}$ quartile) & $14(9,23)$ & $15(10,25)$ \\
\hline \multicolumn{3}{|l|}{ Tumor Location } \\
\hline $\begin{array}{l}\text { Ascending (Ascending, Cecum, } \\
\text { Hepatic flexure, Transverse) }\end{array}$ & $71(58.2 \%)$ & $72(59.0 \%)$ \\
\hline $\begin{array}{l}\text { Descending (Descending, } \\
\text { Sigmoid, Splenic flexure) }\end{array}$ & $45(36.9 \%)$ & $46(37.7 \%)$ \\
\hline Colon NOS & $6(4.9 \%)$ & $4(3.3 \%)$ \\
\hline \multicolumn{3}{|l|}{ T Stage } \\
\hline T3 & $107(87.7 \%)$ & $109(89.3 \%)$ \\
\hline $\mathrm{T} 4$ & $15(12.3 \%)$ & $13(10.7 \%)$ \\
\hline \multicolumn{3}{|l|}{ MMR Status } \\
\hline Deficient & $11(9.0 \%)$ & $21(17.2 \%)$ \\
\hline Proficient & $111(91.0 \%)$ & $101(82.8 \%)$ \\
\hline \multicolumn{3}{|l|}{ Lympho-vascular Invasion } \\
\hline Yes & 7 (5.7 \%) & $6(4.9 \%)$ \\
\hline No & $95(77.9 \%)$ & $97(79.5 \%)$ \\
\hline Not Reported & $20(16.4 \%)$ & $19(15.6 \%)$ \\
\hline
\end{tabular}

pathologic $\mathrm{T}$ stage, tumor grade, MMR status and LVI status) revealed no statistically significant association with patient race (data not shown).

\section{Discussion}

Colorectal cancer is the third most common cancer in men and women in the United States and has the third highest mortality rate in both genders [1]. Relative to CA patients, AA patients with colorectal cancer have a higher incidence, higher mortality, and worse stagespecific outcomes $[1,9]$. The reasons for these disparities are not well understood. The recent improvement in survival of patients with colorectal cancer across all stages has not been seen equally in AA and CA patients: the overall mortality rate has steadily abated in the last three decades, but the decline is less pronounced among
AA compared to CA populations [1, 4]. The mortality rate among AA populations with colorectal cancer at all stages is in dispute, with some studies showing worse rates among AA patients with all stages, including early stage disease $[10,11]$ while others show the trend only for those with advanced stage disease $[4,9]$.

The higher colorectal cancer incidence and mortality rates among AA have been attributed to differences in socioeconomic status leading to lack of access to healthcare, although this has been disputed by others $[2,12]$. Lack of access to healthcare, resulting in lower rates of screening and more advanced stage at presentation and consequently higher mortality, has been noted for the AA population $[12,13]$. In Medicare beneficiaries, there is evidence for a difference in the treatment received for colon cancer [13]; for younger populations, there is also evidence of lower utilization of available treatment with chemotherapy and radiation among AAs [2, 14]. In contrast, studies of the Veterans Affairs Health Care Systems did not find a statistical difference in overall survival between AA and CA patients with colorectal carcinoma and suggested that uniform treatment of their patient population may be the reason for the lack of a difference in survival $[15,16]$. Albain and colleagues reported that in prospective SWOG studies there was no difference in outcomes between AA and CA patients with respect to colon cancer, although AA patients with breast, prostate, or ovarian cancers had worse overall survival than CA patients; however, the small sample size and restriction of analysis to only those who were receiving adjuvant chemotherapy may have played a role in the differential results for colon cancer versus other tumor types [17].

Objective clinical factors have also been examined to identify underlying reasons for the racial disparity. A retrospective analysis of patients with colon cancer not receiving chemotherapy showed a higher mortality for AA subjects [10]. The difference in disease progression and worse mortality may be attributed to variations in tumor pathobiology in patients of different race and ethnicity $[18,19]$. Several studies $[5,11]$, including a study conducted by University of Alabama, Birmingham investigators found that, although there was no difference in the distribution of tumor grade between $\mathrm{AA}$ and $\mathrm{CA}$ colon cancer patients, AAs with high-grade (poorly differentiated) tumors were at three times higher risk of dying of colorectal cancer as CA patients even after controlling for treatment and prognostic factors [20].

This is the first study to compare the 12-gene assay in colon cancer among AA and CA patients. This assay has been validated to predict the recurrence rate in patients with resected stage II colon cancer, whether treated with surgery alone or with surgery followed by adjuvant chemotherapy. We compared the Recurrence Score 

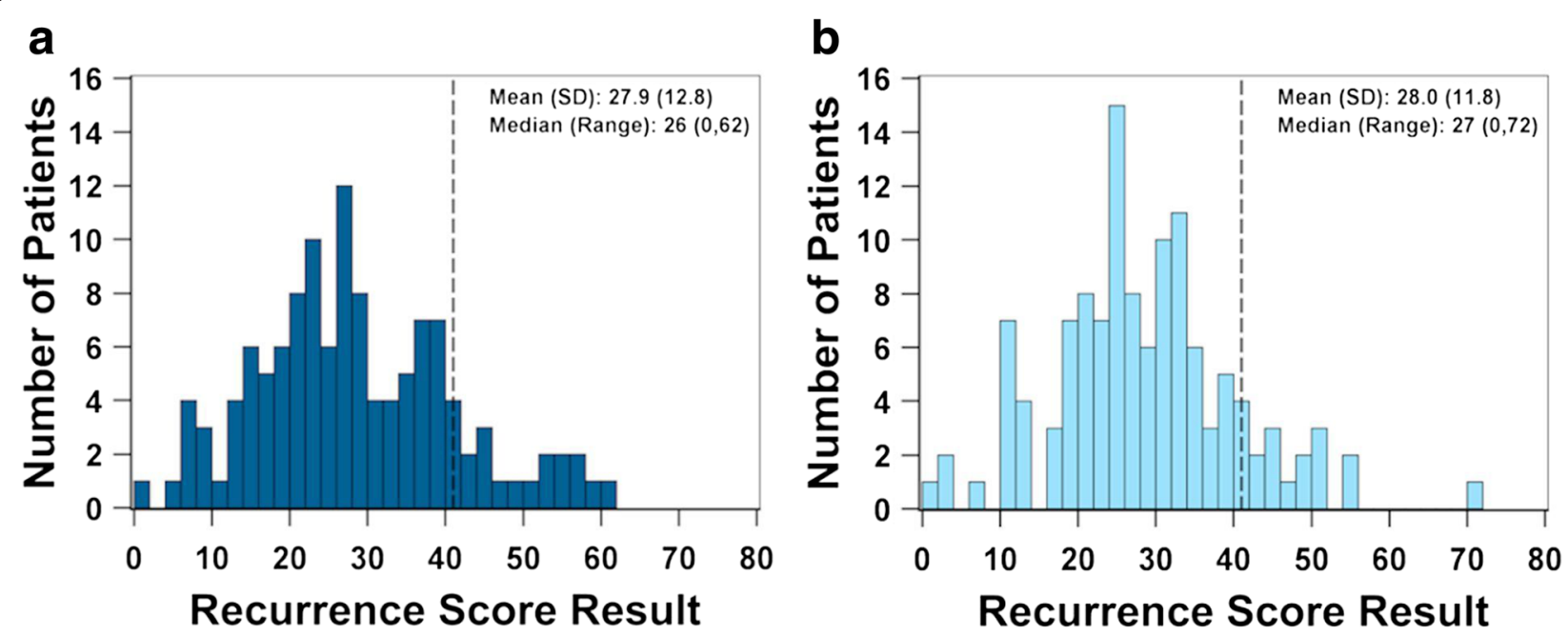

Fig. 2 The distribution of Recurrence Score results for African-American patients and Caucasian patients. The number of patients with a given Recurrence Score result is displayed on the vertical axis; the Recurrence Score values are displayed on the horizontal axis. The mean, SD, median, and range of the Recurrence Score result are inset in each graph. Panel a: display of the Recurrence Score results for AA patients $(n=122)$. Panel $\mathbf{b}$ : display of the Recurrence Score results for CA patients $(n=122)$. The mean Recurrence Score result for African-American patients (27.9 \pm 12.8$)$ was not statistically different from that of Caucasian patients $(28.1 \pm 11.8)$. The vertical line at 41 represents the cutoff for the high Recurrence Score risk group [6]. SD: standard deviation; AA: African-American; CA: Caucasian

results of $\mathrm{AA}$ and $\mathrm{CA}$ patients who otherwise showed no differences in demographic or clinical factors. Although the number of genes assessed by the Oncotype DX assay is limited in number, the genes are known to be involved in cancer biology, therefore, the assay represents a useful, although not comprehensive, probe into the biology of these tumors. Among both AA and CA patients, there was a similar distribution of Recurrence Score results and equal numbers of subjects in both groups had high Recurrence Score results $\geq 41$. The year

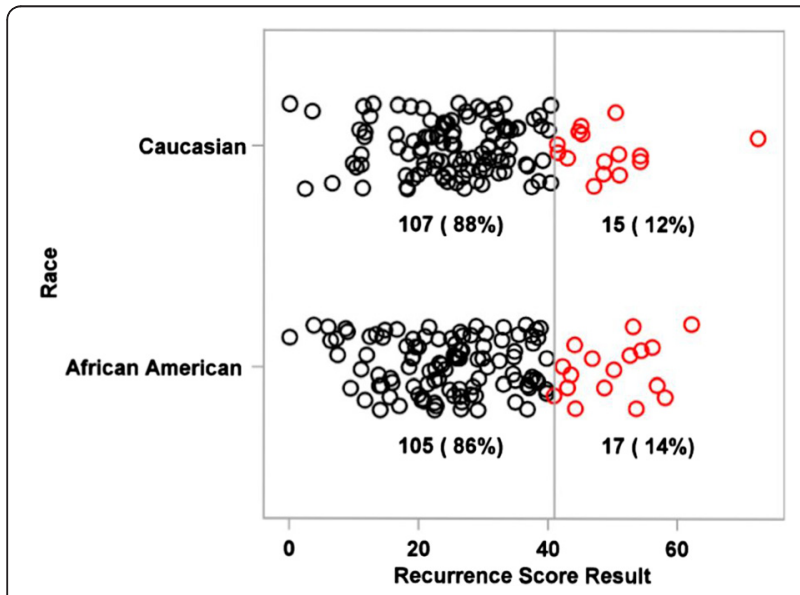

Fig. 3 Recurrence Score result display by high recurrence risk cut off. The Recurrence Score result for each patient is displayed as a circle by ethnicity group. The Recurrence Score results $>41$ are colored red. The proportion of patients with high Recurrence Score values $(\geq 41)$ was similar between the patient groups (17/122 African-American patients; 15/122 Caucasian patients) of diagnosis was matched for the two groups to balance for any inequality in the number of lymph nodes harvested due to the introduction of new standards [21]. We did not exclude patients with fewer than 12 nodes examined because the aim of the study was to evaluate the expression of the genes underlying the biology of colon tumors in AA and CA patients, and not to evaluate the risk of recurrence. None of the gene expression variables, either gene groups or single genes (cell cycle group, stromal group, BGN1, FAP, INHBA1, Ki67, MYBL2, cMYC, and GADD45B), was significantly different between the patient groups.

A limitation of this study is that the assessment of genes was limited to those represented by the 12-gene assay. Accordingly, we cannot rule out the possibility of other underlying differences in tumor biology and molecular profiles between AA and CA patients. Further, as we did not have access to long-term clinical outcomes for patients in this study, we were unable to assess whether similarities in gene expression profiles for AA and CA patients are associated with similar clinical outcomes. Finally, although the AA and CA cohorts were matched based on year of diagnosis, age, and sex, the retrospective nature of this study does not preclude other potential sources of selection bias.

\section{Conclusion}

The distribution of Recurrence Score results, gene expression levels of gene groups and individual genes were not significantly different between AA and CA patients; 


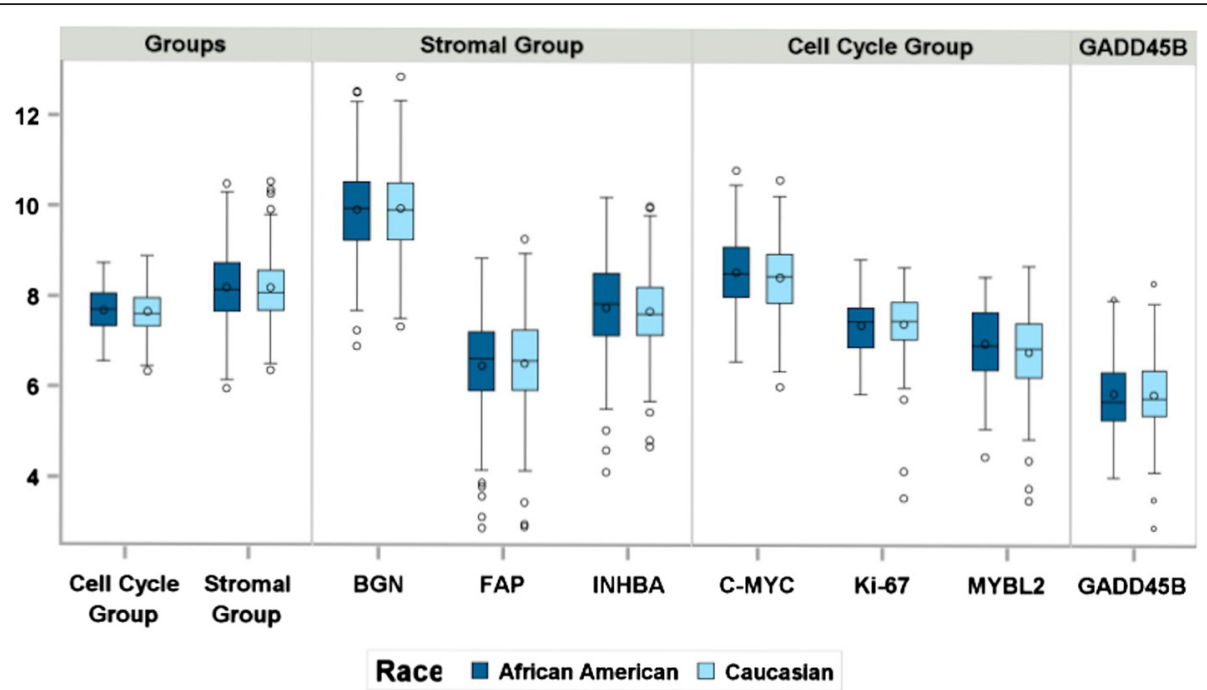

Fig. 4 Distribution of the Gene Expression Levels for Gene Groups and Individual Genes. Gene expression variables, either single genes or gene groups, (Cell Cycle group, Stromal group, BGN, FAP, INHBA, Ki67, MYBL2, C-MYC, and GADD45B) were not significantly different between the racial groups

suggesting tumor biology, as measured by the 12-gene assay, did not differ between patient groups.

\section{Abbreviations}

AA: African American; CA: Caucasian; MMR: Mismatch Repair; FFPE: Formalinfixed Paraffin Embedded; LVI: Lymphatic Vascular Invasion; SWOG: Southwest Oncology Group; UAB: University of Alabama; UAMS: University of Arkansas for Medical Sciences.

\section{Acknowlegments}

Editorial and writing support was provided by Eric R. Schuur, PhD.

\section{Authors' contributions}

RG contributed to the conception and design, data collection, analysis and interpretation, manuscript drafting, revising, and approval for publishing; JP contributed to the conception and design, data collection, analysis and interpretation, manuscript drafting, revising, and approval for publishing; CC contributed to the conception and design, data collection, analysis and interpretation, manuscript drafting, revising, and approval for publishing; RL contributed to the data analysis and interpretation; manuscript drafting and revising; TJ contributed to the tissue procurement, data collection and manuscript approval for publishing; AYJ contributed to the data collection and manuscript approval; AJ contributed to the data collection and manuscript approval; FM contributed to the data collection and manuscript approval; RO contributed to the conception and design, data collection, analysis and interpretation, manuscript drafting, revising, and approval for publishing; and UM contributed to the conception and design, tissue procurement, data collection, analysis and interpretation, manuscript drafting, revising, and approval for publishing. All authors have read and approved the manuscript.

\section{Availability of data and materials}

The data set used is stored in the clinical trials office at the University of Arkansas for Medical Sciences and the clinical trials office at the Central Arkansas Veterans Healthcare System where they can be accessed.

\section{Funding}

This study was supported by funds from Genomic Health, Inc.

\section{Competing interests}

Calvin Chao and Ruixiao Lu report employment by Genomic Health, Inc. The other authors report no conflicts of interest.

\section{Ethics approval and consent to participate}

This study was approved by the following Institutional Review Boards: University of Arkansas IRB committee; Central Arkansas Veterans Healthcare System IRB and R\&D (Research and Development); the Institutional Review Board of the University of Tennessee and the Baptist Memorial Healthcare Corporation, Memphis, TN; and the Institutional Review Board of the University of Alabama at Birmingham. In accordance with the approvals, informed consent from the patients was not required.

\section{Author details}

'University of Arkansas for Medical Sciences, 4301 W Markham, Slot 508, Little Rock, AR 72205, USA. ${ }^{2}$ University of Alabama at Birmingham Comprehensive Cancer Center, Birmingham, AL, USA. ${ }^{3}$ Genomic Health Inc, Redwood City, CA; Genomic Health, Inc., Redwood City, CA, USA. ${ }^{4}$ Boston Baskin Cancer Foundation, Baptist Cancer Center, Memphis, TN, USA.

Received: 17 December 2015 Accepted: 16 May 2016

Published online: 18 June 2016

\section{References}

1. Siegel RL, Miller KD, Jemal A. Cancer statistics, 2015. CA Cancer J Clin. 2015; 65(1):5-29.

2. Govindarajan R, Shah RV, Erkman LG, Hutchins LF. Racial differences in the outcome of patients with colorectal carcinoma. Cancer. 2003;97(2):493-8.

3. Polite BN, Dignam JJ, Olopade OI. Colorectal cancer model of health disparities: understanding mortality differences in minority populations. J Clin Oncol. 2006; 24(14):2179-87.

4. Robbins AS, Siegel RL, Jemal A. Racial disparities in stage-specific colorectal cancer mortality rates from 1985 to 2008. J Clin Oncol. 2012;30(4):401-5.

5. Mayberry RM, Coates RJ, Hill HA, Click LA, Chen WW, Austin DF, Redmond CK, Fenoglio-Preiser CM, Hunter CP, Haynes MA et al. Determinants of black/white differences in colon cancer survival. J Natl Cancer Inst. 1995; 87(22):1686-93.

6. Gray RG, Quirke P, Handley K. Validation study of a quantitative multi-gene RT-PCR assay for assessment of recurrence risk in stage II colon cancer patients. J Clin Oncol. 2011;29:4611-9.

7. Venook AP, Niedzwiecki D, Lopatin M, Ye X, Lee M, Friedman PN, Frankel W, Clark-Langone K, Millward C, Shak S et al. Biologic determinants of tumor recurrence in stage II colon cancer: validation study of the 12-gene recurrence score in cancer and leukemia group B (CALGB) 9581. J Clin Oncol. 2013;31(14):1775-81.

8. Yothers G, O'Connell MJ, Lee M, Lopatin M, Clark-Langone KM, Millward C, Paik S, Sharif S, Shak S, Wolmark N. Validation of the 12-Gene Colon Cancer 
Recurrence Score in NSABP C-07 As a Predictor of Recurrence in Patients With Stage II and III Colon Cancer Treated With Fluorouracil and Leucovorin (FU/LV) and FU/LV Plus Oxaliplatin. J Clin Oncol. 2013;31(36):4512-9.

9. Soneji S, lyer SS, Armstrong K, Asch DA. Racial disparities in stage-specific colorectal cancer mortality: 1960-2005. Am J Public Health. 2010;100(10):1912-6.

10. Alexander D, Chatla C, Funkhouser E, Meleth S, Grizzle WE, Manne U. Postsurgical disparity in survival between African Americans and Caucasians with colonic adenocarcinoma. Cancer. 2004;101(1):66-76.

11. Potosky AL, Harlan LC, Kaplan RS, Johnson KA, Lynch CF. Age, sex, and racial differences in the use of standard adjuvant therapy for colorectal cancer. J Clin Oncol. 2002;20(5):1192-202

12. Ciccone G, Prastaro C, Ivaldi C, Giacometti R, Vineis P. Access to hospital care, clinical stage and survival from colorectal cancer according to socioeconomic status. Ann Oncol. 2000;11(9):1201-4.

13. White A, Vernon SW, Franzini L, Du XL. Racial and ethnic disparities in colorectal cancer screening persisted despite expansion of Medicare's screening reimbursement. Cancer Epidemiol Biomarkers Prev. 2011;20(5):811-7.

14. Gross CP, Smith BD, Wolf E, Andersen M. Racial disparities in cancer therapy: did the gap narrow between 1992 and 2002? Cancer. 2008;112(4):900-8.

15. Page WF, Kuntz AJ. Racial and socioeconomic factors in cancer survival. A comparison of Veterans Administration results with selected studies. Cancer. 1980:45(5):1029-40.

16. Zullig LL, Carpenter WR, Provenzale D, Weinberger M, Reeve BB, Jackson GL. Examining potential colorectal cancer care disparities in the Veterans Affairs health care system. J Clin Oncol. 2013;31(28):3579-84.

17. Albain KS, Unger JM, Crowley JJ, Coltman Jr CA, Hershman DL. Racial disparities in cancer survival among randomized clinical trials patients of the Southwest Oncology Group. J Natl Cancer Inst. 2009;101(14):984-92.

18. Chen CL, Liu Q, Relling MV. Simultaneous characterization of glutathione $\mathrm{S}$-transferase $\mathrm{M} 1$ and $\mathrm{T} 1$ polymorphisms by polymerase chain reaction in American whites and blacks. Pharmacogenetics. 1996;6(2):187-91.

19. Zhong S, Wyllie AH, Barnes D, Wolf CR, Spurr NK. Relationship between the GSTM1 genetic polymorphism and susceptibility to bladder, breast and colon cancer. Carcinogenesis. 1993;14(9):1821-4.

20. Alexander D, Jhala N, Chatla C, Steinhauer J, Funkhouser E, Coffey CS, Grizzle WE, Manne U. High-grade tumor differentiation is an indicator of poor prognosis in African Americans with colonic adenocarcinomas. Cancer. 2005;103(10):2163-70.

21. Sobin LH. TNM: principles, history, and relation to other prognostic factors. Cancer. 2001;91(8 Suppl):1589-92.

\section{Submit your next manuscript to BioMed Central and we will help you at every step:}

- We accept pre-submission inquiries

- Our selector tool helps you to find the most relevant journal

- We provide round the clock customer support

- Convenient online submission

- Thorough peer review

- Inclusion in PubMed and all major indexing services

- Maximum visibility for your research

Submit your manuscript at www.biomedcentral.com/submit

C Biomed Central 